\title{
A EDUCAÇÃO FÍSICA E O DESENVOLVIMENTO DA AUTONOMIA DE UMA ALUNA COM PARALISIA CEREBRAL DIPLÉGICA ESPÁSTICA: UMA PERSPECTIVA DE INCLUSÃO
}

\section{PHYSICAL EDUCATION AND DEVELOPMENT OF THE AUTONOMY OF A STUDENT WITH SPASTIC DIPLEGIC CEREBRAL PALSY: AN INCLUSION PERSPECTIVE}

\author{
${ }^{1}$ José Luiz Fabris \\ ${ }^{2}$ Emilene Coco dos Santos \\ ${ }^{3}$ Jamille Locatelli* \\ ${ }^{4}$ Graziela de Jesus Veronez
}

\begin{abstract}
${ }^{1}$ Instituto Federal do Espírito Santo. E-mail: joseluiz@ifes.edu.br ${ }^{2}$ Instituto Federal do Espírito Santo. E-mail: emilene.coco@ifes.edu.br ${ }^{3}$ Instituto Federal do Espírito Santo. E-mail: jamille.locatelli@ifes.edu.br ${ }^{4}$ Instituto Federal do Espírito Santo. E-mail: grazij2010@hotmail.com

*Autor de correspondência
\end{abstract}

Artigo submetido em 03/03/2020, aceito em 08/05/2020 e publicado em 28/08/2020.

Resumo: O objetivo deste estudo foi identificar as contribuições das aulas de Educação Física no desenvolvimento da autonomia de uma aluna com paralisia cerebral diplégica espástica, com idade de 17 anos, cursando o segundo ano de Curso Técnico Integrado ao Ensino Médio na rede pública federal de ensino. A paralisia cerebral é resultado de desordens permanentes do desenvolvimento do movimento e postura, atribuída a um distúrbio não progressivo que ocorre durante a formação do cérebro na fase fetal ou na infância, podendo afetar o aspecto motor, associado ou não a outros distúrbios sensoriais, cognitivos, comportamentais, dentre outros. Neste trabalho, utilizou-se o estudo de caso como método de pesquisa com caráter qualitativo. A investigação foi realizada no primeiro semestre do ano de 2019, levando em consideração a vivência da aluna nas aulas de Educação Física do ano anterior. Os resultados mostraram que as aulas realizadas em uma escola da rede pública federal de ensino, localizada no município de Colatina, ES, proporcionaram à aluna a percepção de maior autonomia e consciência corporal, além de facilitar a socialização com os sujeitos escolares daquela instituição. Apesar da condição física, considerar as possibilidades de participação da aluna nas diferentes propostas de exercícios pode contribuir para que ela adquira mais flexibilidade e força, possibilitando avanços significativos em sua autonomia.

Palavras-chave: Educação Física; paralisia cerebral; ensino médio integrado. 


\begin{abstract}
The aim of this study was to identify the contributions of Physical Education classes in the development of the autonomy of a student with spastic diplegic cerebral palsy, aged 17 years, attending the second year of Technical Course Integrated to High School in the federal public school system. Cerebral palsy is the result of permanent disorders of the development of movement and posture, attributed to a non-progressive disorder that occurs during the formation of the brain in the fetal phase or in childhood, and may affect the motor aspect, associated or not with other sensory, cognitive, behavioral disorders, among others. In this work, the case study was used as a qualitative research method. The research was carried out in the first semester of 2019, taking into account the student's experience in physical education classes of the previous year. The results showed that the classes held in a federal public school, located in the municipality of Colatina, ES, provided the student with the perception of greater autonomy and body awareness, besides facilitating socialization with the school subjects of that institution. Despite the physical condition, considering the possibilities of the student's participation in the different proposals of exercises can contribute to her acquiring more flexibility and strength, enabling significant advances in her autonomy.
\end{abstract}

Keywords: Physical Education; cerebral palsy; integrated high school.

\section{INTRODUÇÃO}

A inclusão escolar das pessoas com necessidades específicas no ensino comum ainda demanda estudo, planejamento, adequação curricular, dentre outros elementos constitutivos da educação, que garantam a apropriação do conhecimento. No ensino médio, muitos desafios surgem, em relação às especificidades desses alunos, principalmente considerando as barreiras arquitetônicas, culturais, curriculares e pedagógicas. Para os que necessitam de atenção, devido à sua necessidade específica, como no caso dos alunos com prejuízos na mobilidade e no equilíbrio, as aulas de Educação Física podem contribuir com o desenvolvimento da autonomia desses e proporcionar melhorias significativas na participação das atividades desenvolvidas nas aulas, em outros espaços acadêmicos e na sua vida diária.

A paralisia cerebral (PC) é resultado de desordens permanentes do desenvolvimento do movimento e postura atribuídos a um distúrbio não progressivo que ocorre durante a formação do cérebro na fase fetal ou na infância, podendo afetar o aspecto motor, associado ou não a outros distúrbios sensoriais, cognitivos, comportamentais (BRASIL, 2014).

De acordo com as Diretrizes de Atenção à Pessoa com PC (BRASIL,
2014), existem três maneiras de classificar a PC a partir de suas características clínicas, podendo ser discinética, atáxica e espástica. A primeira caracteriza-se por movimentos atípicos e involuntários, ocasionada por uma lesão do sistema extrapiramidal. A paralisia cerebral atáxica caracteriza-se por um distúrbio da coordenação dos movimentos em razão da dissinergia, apresentando, usualmente, uma marcha com aumento da base de sustentação e tremor, que é ocasionada por uma disfunção no cerebelo (ROSENBAUM et al., 2007). De modo genérico, a terceira decorre de espasmos na musculatura pela presença de tônus elevado e é ocasionada por uma lesão nos neurônios do sistema piramidal (BRASIL, 2014).

O foco de estudo neste trabalho foi a paralisia cerebral espástica, diagnóstico recebido pela aluna Ana ${ }^{1}$. Esse tipo se caracteriza pelo aumento do tônus muscular, diminuição de força muscular e hiperreflexia. A lesão pode aparecer no córtex motor ou no trato piramidal do cérebro (sistema piramidal). Dependendo do local onde a lesão ocorre, diferentes partes do corpo são afetadas e cada vez

\footnotetext{
${ }^{1}$ Para manter a identidade da aluna resguardada, será utilizado um nome fictício - Ana - todas as vezes que houver referência à discente.
} 
mais, os movimentos são restritos em amplitude e requerem excessivo esforço; apresenta-se em quatro tipos, de acordo com a área do corpo lesionada: hemiplégica espástica, diplégica espástica, triplégica espástica e a tetraplégica espástica (MATOS, 2011).

No Brasil, acompanhamos, no final do século XX, mudanças na legislação que discute a participação social da pessoa com deficiência, em consonância com o que foi acordado na Convenção das Nações Unidas pelos Direitos das Pessoas com Deficiência, em 2006. Muitos instrumentos legais foram criados e implementados para garantir $o$ acesso de pessoas com deficiência aos serviços de educação, saúde e práticas esportivas (BRASIL, 2013a; BRASIL, 2013b; BRASIL, 2015). O principal objetivo de tais instrumentos é garantir a oferta e a participação de todos nas atividades esportivas como forma de lazer, reabilitação e inserção social. Para atingir essa meta, é necessária a elaboração de programas específicos para essa população e a capacitação profissional da equipe de trabalho, com propostas de atividades que considerem as peculiaridades no desenvolvimento das pessoas com deficiência.

A Educação Física escolar proporciona momentos que possibilitam o contato consigo mesmo e com o outro, permitindo a descoberta das habilidades, limitações e potencialidades de cada um. O processo de socialização por meio do esporte e do lazer pode contribuir para a aquisição de autoconfiança, de capacidade de fazer escolhas, de tomada de decisão, de maior independência e autonomia do indivíduo, dentre outras que garantam às pessoas com deficiência desfrutarem de sua cidadania plena.

Apesar de os benefícios do exercício físico já serem conhecidos há décadas, o maior desafio ainda é incluir os alunos com deficiência nas aulas de Educação Física em escolas regulares. Para Diehl (2008), é fundamental que a prática de exercícios supere o intuito único da integração do deficiente, mas que possibilite a conscientização sobre a importância da prática também em espaços de lazer.

De maneira geral, os indivíduos deficientes tendem a apresentar um estilo de vida sedentário, devido a possíveis limitações advindas da deficiência ou mesmo da falta de acessibilidade aos locais próprios para a prática de exercícios (HADDAD et al., 1997; ZUCHETTO e CASTRO, 2002; RIMMER et al., 2004).

A prática regular de exercícios físicos está associada a diversos benefícios para a saúde, dentre eles, aumento dos níveis de força e resistência musculares, redução da pressão arterial (GUIMARÃES et al. 2010; LOCATELLI et al., 2018), dentre outros. Há também evidências importantes de que o exercício tenha um impacto positivo em diversos parâmetros cognitivos e emocionais; ele está ainda associado a um menor risco de declínio cognitivo (COLCOMBE e KRAMER, 2003; MARMELEIRA, 2013).

Diante desse cenário, se torna fundamental a inclusão dos alunos deficientes nas aulas de Educação Física, haja vista que o exercício físico sistematizado poderá proporcionar autonomia na realização das atividades da vida diária desses indivíduos, principalmente para aqueles com mobilidade reduzida (YOSHIDA et al., 2010).

É importante destacar ainda que a inclusão desses alunos nas aulas também poderá estimulá-los a manter um estilo de vida ativo durante a fase adulta. Ademais, a prática de exercício pelas pessoas com deficiência pode ser um mecanismo facilitador de sua inclusão na sociedade e proporcionador da melhora da autoestima. (ZUCHETTO e CASTRO, 2002). Mas qual é a percepção deles sobre essas melhorias? De que maneira a Educação Física pode contribuir para o desenvolvimento da autonomia das pessoas com PC? Essas questões serão discutidas na apresentação dos dados deste estudo. 
Considerando esse pressuposto, o objetivo deste estudo foi identificar as contribuições das aulas de Educação Física no desenvolvimento da autonomia de uma aluna com Paralisia Cerebral Diplégica Espástica (PCDE), de 17 anos, cursando o segundo ano de um curso técnico integrado ao ensino médio na rede pública federal de ensino da cidade de Colatina, ES, Brasil.

A relevância do estudo se dá pela escassez de trabalhos científicos sobre o tema, que tenham como campo de estudo a escola comum, e a necessidade de avançarmos nas discussões sobre os benefícios da Educação Física sobre o desenvolvimento da autonomia de pessoas com PCDE. Algumas questões nortearam o desenvolvimento deste estudo e foram direcionadas à aluna, a saber: as aulas de Educação Física contribuíram em que para o seu cotidiano? Para você, o que é necessário fazer para que as pessoas com PCDE participem mais efetivamente das aulas de Educação Física? Essas questões também nortearam o planejamento das aulas de Educação Física para o processo de inclusão escolar da aluna Ana, a partir de 2018 (quando ela se encontrava no primeiro ano de um curso técnico integrado ao ensino médio) até o presente momento.

\section{PROCESSOS METODOLÓGICOS: MATERIAIS E MÉTODOS}

Neste estudo utilizamos a abordagem qualitativa por meio de um estudo de caso, com o intuito de atender ao objetivo proposto, no que se refere à análise das contribuições das aulas de Educação Física no desenvolvimento da autonomia de uma aluna matriculada no segundo ano de um curso técnico integrado ao ensino médio de uma escola da rede pública federal de ensino, localizada no município de Colatina, ES. Esta pesquisa foi realizada no primeiro semestre do ano de 2019, levando em consideração a vivência da aluna nas aulas de Educação Física no ano anterior, cursado na mesma escola.
$\mathrm{O}$ estudo de caso - enquanto método de investigação qualitativa contribui para que o pesquisador tenha uma compreensão extensiva, com mais objetividade e validade conceitual, sobre o objeto a ser estudado. Nesta pesquisa, o chamado estudo de caso intrínsico mostrou-se mais apropriado, pois havia o interesse em conhecer melhor o indivíduo nas aulas de Educação Física, ou seja, conhecer as características do caso (YIN, 2010).

A aluna participante do estudo tinha, à época, 16 anos e diagnóstico de PCDE, com baixa mobilidade e espasmos nos membros superiores, utilizava andador ou cadeira de rodas para se locomover na escola.

A baixa mobilidade ocasionada pela PCDE não permitia que Ana participasse adequadamente das atividades propostas para a sua turma; inicialmente, ficou excluída. Um comentário feito por Ana a um dos professores de Educação Física sobre suas quedas constantes e a necessidade de ter alguém para ajudá-la a se levantar o fez perceber uma possibilidade: usar os momentos das aulas para fortalecer os músculos da discente, melhorar a flexibilidade e agilidade, a fim de ela poder alcançar autonomia no cotidiano. Houve, também, a preocupação em tornar as aulas mais produtivas para Ana e a turma.

Diante desse relato e da observação das necessidades de Ana, os professores planejaram as aulas privilegiando a realização de atividades motoras para membros superiores e inferiores, com o intuito de fortalecê-los, desenvolver a autonomia e contribuir com a inclusão social da aluna. $\mathrm{O}$ planejamento participativo foi considerado em todos os momentos do processo educativo. Além de atividades voltadas para o fortalecimento muscular, os professores deram ênfase as que proporcionassem aumento da coordenação motora e da flexibilidade da aluna. Para tanto, foram utilizadas bolas de diferentes tamanhos e pesos (Basquetebol, 
Voleibol, medicine ball), cordas, cones, arcos, faixas elásticas, bancos suecos, mesa, colchão de espuma, bastões, escadas e rampas, respeitando as possibilidades da aluna. Os movimentos realizados nas atividades envolviam flexão e extensão de joelhos, flexão e adução de quadril, adução de escápulas, extensão de cotovelos e alongamentos dos músculos peitoral, tríceps braquial, quadríceps femoral, posteriores da coxa, peitoral e da cintura escapular.

O programa de atividades planejado para Ana foi realizado no ano de 2018, durante as aulas de Educação Física, que aconteciam duas vezes por semana e tinham duração de 50 minutos cada. No total, foram realizadas 72 aulas.

A coleta de dados foi feita por meio de entrevista, análise de documentos arquivados da escola e de relatos dos professores de Educação Física e de um dos cuidadores, que acompanharam a aluna. André (2008, p.51) considera que "[...] a entrevista cumpre um papel fundamental e é através dela que o pesquisador vai conhecer a visão de mundo e/ou a representação que os sujeitos têm de determinado objeto ou de sua condição". O roteiro da entrevista foi planejado pelos autores de forma objetiva, com perguntas abertas e claras para serem respondidas pela aluna, após o consentimento do responsável e o dela sobre a realização do estudo, e gravadas pelos pesquisadores em aplicativo de gravação de áudio (app Gravador iPhone Apple ${ }^{\circledR}$ ).

Outro procedimento utilizado foi a análise documental, tendo em vista a necessidade de apreensão de informações que constavam em registros documentais da escola, a fim de possibilitar a compreensão do processo de escolarização da aluna no ensino fundamental e no seu primeiro ano no curso técnico integrado ao ensino médio. Lüdke e André (1986, p. 39) apontam que os documentos são uma fonte de dados " [...] de onde podem ser retiradas evidências que fundamentem afirmações e declarações do pesquisador. Representam ainda uma fonte de informação contextualizada, mas surgem num determinado contexto e fornecem informações sobre esse mesmo contexto". Os autores ainda afirmam que a análise documental é importante, pois, "[...] como técnica exploratória, indica problemas que devem ser mais bem explorados através de outros métodos. Além disso ela pode complementar as informações obtidas por outras técnicas de coleta" (LÜDKE E ANDRÉ, 1986, p. 39), auxiliando na análise das informações coletadas na entrevista, como no caso dessa investigação.

Os relatos dos professores e do cuidador auxiliaram na compreensão do processo de escolarização, e a análise dos arquivos contribuiu para contextualizar a história de vida da aluna, principalmente sobre suas experiências motoras.

\section{RESULTADOS E DISCUSSÃO}

A escolarização de Ana no ensino fundamental foi realizada em uma escola municipal no interior do município de Colatina. De acordo com o Relatório Inicial de Atendimento analisado na escola pública federal, a família da aluna relatou que ela se sentia excluída nas aulas de Educação Física, quando estudava na escola anterior. Para a própria Ana havia carência de uma estrutura apropriada para a prática de exercícios físicos naquele espaço escolar. Ela informou que não havia tentativa de participação nas aulas e parecia não existir propostas diferenciadas que proporcionassem a sua inclusão nas atividades.

Geralmente me davam uma bola ou eu ficava conversando com as outras meninas que não gostavam de Educação Física. Lá não tinha quadra de Basquete, Vôlei. A quadra ficava fora da escola, na comunidade, e isso era um obstáculo. Quando eu não tinha a cadeira de roda disponível eu ficava na escola sozinha fazendo alguma coisa. Eu dependia de outra pessoa para trazer a cadeira de rodas. Em sala de aula tinha uma estagiária 
de Pedagogia que me ajudava a copiar a matéria, ir ao banheiro (ENTREVISTA, 10/04/2019).

Nota-se que a presença da aluna não foi suficiente para promover a ruptura do paradigma da exclusão das aulas de Educação Física. Grande parte dos professores ainda considera um desafio incluir os alunos com deficiências nas aulas regulares. Além disso, segundo Ana, a falta de estrutura na escola também dificultou a vivência de toda a sua turma nos esportes coletivos, tais como o Voleibol e o Baquetebol. Ao invés de praticá-los, estudavam a teoria (história e regras), mas sentiam falta de praticar o jogo dessas modalidades esportivas coletivas que fazem parte da cultura corporal de movimento (COLETIVO DE AUTORES, 1992). De acordo com Ana, "[...] geralmente eram aulas teóricas sobre os esportes, pois não haviam quadras equipadas adequadamente para os esportes. $\mathrm{O}$ esporte que mais pratiquei na escola foi o Handebol, no gol. Era um jogo adaptado" (ENTREVISTA, 10/04/2019).

Sebastião e Freire (2009) defendem que os materiais didáticos são indispensáveis à Educação Física, devido às suas especificidades. Prandina e Santos (2016) e Ferreira e Nascimento (2017) relatam que os materiais são precários, assim como o espaço adequado para a realização das aulas de Educação Física. Os professores destacam que possuem, na maioria das vezes, somente um pátio ou quadra sem cobertura e poucas bolas para a prática dos exercícios e realização das vivências corporais (PRANDINA e SANTOS, 2016).

A chegada de Ana à escola atual exigiu a organização do ambiente escolar, com revezamento dos servidores (docentes e técnicos-administrativos) para recebê-la e direcioná-la às atividades acadêmicas. A turma era composta de 43 alunos, sendo 32 meninos e 11 meninas. $\mathrm{O}$ número elevado de alunos demandava mais atenção por parte dos servidores (docentes e técnicosadministrativos). Quando Ana chegou à escola, estava na "defensiva", não queria utilizar a cadeira de rodas, pois julgava que poderia ficar de lado nas atividades, como acontecia nas aulas de Educação Física da escola anterior. Porém, todos os servidores acreditavam que Ana perderia muito tempo para se locomover entre os andares e salas e que seria um esforço maior usar o andador para esse fim. Com a insistência dos profissionais, dos membros do Núcleo de Acompanhamento às pessoas com Necessidades Específicas, da equipe de gestão pedagógica e, principalmente, com o trabalho dos professores de Educação Física, ela passou a aceitar ajuda para se locomover com a cadeira de rodas. Contudo, o rodízio dos profissionais para acompanhá-la ainda era um desafio. Isso evidenciou a necessidade de contratação de dois cuidadores para acompanhá-la, o que ocorreu em outubro de 2018.

Os cuidadores

também desempenharam um trabalho importante na adaptação de Ana, que precisou se acostumar à situação de ter duas pessoas acompanhando-a nas atividades que não conseguia realizar sozinha e na locomoção entre os espaços escolares. Hoje, ela reconhece que consegue participar mais ativamente das propostas acadêmicas com a ajuda dos cuidadores, pois não se atrasa em seus deslocamentos, como, por exemplo: a sair de dentro do transporte escolar e se dirigir à sala de aula; ir da sala de aula para os laboratórios; transitar da sala de aula para a de recursos multifuncionais, a fim de realizar os desdobramentos $^{2}$ avaliativos e receber o atendimento educacional especializado; ir para as aulas de Educação Física. Além de auxiliar na locomoção de Ana e na interação dela com os demais colegas, os cuidadores contribuem, também, na busca, junto com a aluna, pela ajuda dos professores das disciplinas.

${ }^{2}$ Consideramos como desdobramento o tempo disponibilizado a mais para realização de uma atividade avaliativa. 
$\mathrm{Na}$ opinião de Ana, as aulas de Educação Física são importantes para a sua autonomia no momento da locomoção, com o apoio do andador e sem ele. $\mathrm{Na}$ escola, reconhece suas conquistas em relação à sua mobilidade, quando afirma: "Hoje eu subi a rampa sem o andador e desci de costas, que sempre foi um problema para mim" (ENTREVISTA, 10/04/2019).

A aluna ressaltou que, na nova escola, teve a oportunidade de jogar, junto com sua turma Voleibol e Basquetebol adaptados. Para ela, essa adaptação é necessária para sua interação com os outros, pois considera a ajuda dos colegas essencial para o seu desenvolvimento, diz que os "[...] colegas ajudam com a recepção de saque e aí eu realizo o saque. Está muito bom da forma que está, mas eu gostaria de praticar outros esportes com eles, é muito divertido. $\mathrm{O}$ professor adaptou o Basquete e eu pude jogar com meus colegas, foi muito bom" (ENTREVISTA, 10/04/2019).

Ana disse sentir-se mais incluída nas aulas, apesar de em alguns momentos realizar as atividades somente com um dos professores de Educação Física e o cuidador, principalmente aquelas relacionadas ao desenvolvimento da força, do alongamento, da flexibilidade e da caminhada com apoio do andador. A comparação com a escola anterior é inevitável, conforme ela mesma relata: "Antes eu participava pouco e não tinha muita opção. Aqui é muito bom eu tenho mais opções. Estou me sentido mais incluída" (ENTREVISTA, 10/04/2019).

Quando questionada se as atividades desenvolvidas nas aulas de Educação Física colaboraram na realização de outras atividades na escola, Ana respondeu que sim, explicando que:

Ajuda bastante. Principalmente na autonomia. Por exemplo: levantar do banco. Eu tenho que projetar meu centro de gravidade para frente e colocar o peso do meu corpo mais nas pernas. Dessa forma eu não preciso fazer tanta força nos braços.
Levantar do chão. Uma vez eu caí e não precisei chamar ninguém para me ajudar. Eu estava no meu quarto mudando de roupa e eu escorreguei, eu sentei no chão, virei e ajoelhei e consegui levantar. Antes eu precisava de ajuda. A gente treina levantar do chão mesmo. É colocado um colchão no chão e eu sento nesse colchão e eu tenho que virar de barriga para baixo e arrastar os joelhos trazendo o centro de gravidade para frente e preparar os braços para levantar. É colocado o andador na minha frente e eu me apoio nele para levantar (ENTREVISTA, 10/04/2019).

Ana também enfatizou a autonomia que conquistou após o início das práticas adaptadas nas aulas. Nota-se, em sua fala, que os momentos pedagógicos da Educação Física lhe proporcionaram a vivência para que ela se virasse em decúbito ventral, sentasse sobre os pés e buscasse o apoio de um objeto para se levantar. Isso lhe proporcionou certa autonomia para se levantar do chão sem necessitar da ajuda de alguém para dar-lhe suporte, quando precisasse se levantar do chão para assumir o andador. Ana ainda pontuou:

Foi trabalhada a coordenação motora fina. Por exemplo, ao subir a escada eu colocava meu peso na pessoa que estava me ajudando agora eu coloco meu peso sobre as pernas. Hoje eu consigo andar sem o andador e subir a rampa segurando nas mãos dos professores ou nos suportes laterais da rampa (ENTREVISTA, 10/04/2019).

Nessa fala, notamos também o despertar da consciência corporal da aluna, em relação à solicitação muscular para o emprego de força ao subir as escadas. Ela mesma percebeu que antigamente utilizava o apoio com transferência de força a terceiros para se locomover.

Outras questões foram levantadas por Ana quando perguntamos o que ela gostaria de apender nas aulas de Educação Física, além dos jogos coletivos. A aluna inferiu que gostaria de experienciar ações do cotidiano que ela não sabe fazer e que 
ainda não consegue realizar com segurança, como andar de ônibus, se deslocar com mais autonomia com a cadeira de rodas, arrumar seu próprio cabelo entre outras ações que, muitas vezes, fazemos de forma natural. $\mathrm{O}$ ensino dessas tarefas extrapola a prática corporal vivenciada na Educação Física e entendemos que essa experiência deve ser vivida em outros ambientes da vida da aluna, dentre eles, o de casa.

Entendemos que a família também pode contribuir para que Ana participe ativamente das ações na sociedade, a qual nem sempre está preparada para eliminar as barreiras arquitetônicas e atitudinais em uma perspectiva mais inclusiva, para o acesso das pessoas com deficiência a todos os serviços essenciais de transporte, moradia, saúde e educação. Contudo, reconhecemos que não basta a família auxiliar na preparação de Ana para uma vida mais autônoma se a sociedade não transformar a maneira como está organizada, no que diz respeito às mudanças necessárias para que as pessoas com deficiência tenham acesso a todos esses serviços.

Ana nos surpreendeu ao dizer:

Geralmente eu fico pensando o que faria se tivesse que pegar um ônibus sozinha. O que eu teria que fazer? Eu não tenho a ideia do que eu poderia fazer. Gostaria de morar sozinha, mas eu penso como me virar sem alguém para me ajudar. Acho que tenho que aprender a manusear melhor a cadeira de rodas e aprender a usar melhor meu andador (ENTREVISTA, 10/04/2019).

Nessa fala final, Ana demonstra que só quer exercer seu direito de ir e vir e ampliar seu nível de autonomia diante da sociedade. Tem consciência de que é uma jovem com muitos planos para o futuro, mas que sua baixa mobilidade pode atrapalhar seu sucesso, principalmente se não encontrar condições de exercer sua autonomia de locomoção. Esse é um assunto desafiador a ser considerado, mas necessário para que Ana exerça efetivamente seus direitos de cidadã.

Esses relatos nos mostram a necessidade de repensarmos o papel escola, e em especial, o da Educação Física, frente à inclusão dos alunos com deficiências. Nosso olhar, enquanto profissionais da área da Educação deve estar voltado para a promoção de melhorias na autonomia e socialização desses indivíduos, contribuindo para potencializar suas capacidades (que muitas vezes são desconsideradas diante de sua deficiência).

\section{CONCLUSÕES}

Considerando o objetivo proposto para esta investigação, podemos depreender que as aulas de Educação Física realizadas em uma escola da rede pública federal de ensino, localizada no município de Colatina, ES, proporcionaram a uma aluna com PCDE a percepção de maior autonomia e consciência corporal, além de facilitar a socialização com os demais sujeitos da instituição.

Para Ana, participar das aulas de Educação Física poderia ser uma oportunidade para aprender junto com outros alunos e os professores. Apesar de sua condição, considerar as possibilidades de participação da aluna nas diferentes propostas de exercícios possibilitou avanços significativos na apropriação de mobilidade mais independente. Segundo ela, as aulas contribuíram para sua locomoção e ajudaram-na a adquirir mais flexibilidade e força.

Apesar de observarmos uma percepção positiva da aluna, quanto às conquistas proporcionadas pelos exercícios realizados nas aulas, acreditamos que as pesquisas devam se aprofundar no viés metodológico, considerando um número maior de indivíduos, um tempo de intervenção mais extenso e a utilização de instrumentos de avaliação que deem também uma percepção quantitativa dos 
ganhos alcançados. Nessa perspectiva, avançaremos nas investigações dessa natureza que tenham como objetivo promover a inclusão e o desenvolvimento da autonomia de alunos com deficiências.

Esperamos que esses resultados possam instigar outros profissionais a aprimorarem seu fazer pedagógico nas aulas desse importante componente curricular escolar, tendo como objetivo beneficiar os alunos com necessidades específicas.

\section{AGRADECIMENTOS}

Os autores manifestam agradecimento à aluna pela disposição em contribuir valiosamente com seus comentários para a construção deste trabalho.

\section{REFERÊNCIAS}

ANDRÉ, M. E.; DALMAZO, A. Estudo de caso em pesquisa e avaliação educacional. Brasília: Liber Livros. 68 p. (Série Pesquisa: v. 13), 2008.

BRASIL. Estatuto da Pessoa com deficiência. Brasília: Imprensa Oficial, 2013a.

. Viver sem Limite - Plano

Nacional dos Direitos da Pessoa com Deficiência. Brasília: SNPD, 2013b.

Ministério da Saúde. Secretaria de Atenção à Saúde. Departamento de Ações Programáticas Estratégicas. Diretrizes de atenção à pessoa com paralisia cerebral/Ministério da Saúde, Secretaria de Atenção à Saúde, Departamento de Ações Programáticas Estratégicas. Brasília: Ministério da Saúde, 2014.

\section{Lei Brasileira de Inclusão da} Pessoa com Deficiência. Brasília: Imprensa Oficial, 2015.

COLCOMBE, S. J.; KRAMER, A. F. Fitness effects on the cognitive function of older adults: a meta-analytic study.
Psychological Sciences, Columbia, v.14, n.2, p.125-130, 2003.

COLETIVO DE AUTORES. Metodologia do Ensino da Educação Física. São Paulo: Cortez, 1992.

DIEHL, R. M. Jogando com as

Diferenças: jogos para crianças e jovens com deficiência em situação de inclusão e em grupos específicos. 2.Ed. São Paulo: Phorte, 2008.

FERREIRA, D. G.; NASCIMENTO, E. M. F. Dificuldades estruturais e trabalho: desafios de professores de educação física da rede municipal de ensino nas zonas centro oeste e leste da cidade de Manaus/AM. Revista Eletrônica

Mutações, Manaus, v.8, n.14, p.23-40, 2017.

GUIMARÃES GV, CIOLAC EG, CARVALHO VO, D'AVILA VM, BORTOLOTTO LA, BOCCHI EA.

Effects of continuous vs. interval exercise training on blood pressure and arterial stiffness in treated hypertension.

Hypertension Research, Tóquio, v.33, n.6, p.627-32, 2010.

HADDAD S, SILVA PRS, PEREIRA BARRETTO AC, FERRARETTO I. The effect of short term Aerobic physical training using upper limbs in paraplegic persons with mild to moderate hypertension. Arquivos Brasileiros de Cardiologia, Rio de Janeiro, v.69, n.3, p.169-73, 1997.

INSTITUTO FEDERAL DO ESPÍRITO SANTO (IFES). Resolução do conselho superior $\mathbf{n}^{\mathbf{0}} \mathbf{5 5 / 2 0 1 7}$, de 19 de dezembro de 2017. Institui os procedimentos de identificação, acompanhamento e certificação de alunos com Necessidades Específicas no Instituto Federal de Educação, Ciência e Tecnologia do Espírito Santo - Ifes. Disponível em: https://ifes.edu.br/images/stories/publicacoes/conselhos-comissoes/ 
conselho-superior/2017/ Res_CS_55_ 2017_-_Institui_procedimentos_de_ identifica\%C3\%A7\%C3\%A3o_acompanh amento_e_certifica\%C3\%A7\%C3\%A3o_d e_alunos_com_Necessidades_Espe $\%$ C3\% Adficas_-_Alterada_Res_19_2018.pdf. Acesso em: 08 out. de 2019.

LOCATELLI, J.; ARAUJO, D. J.; SENA, H. N.; PRADO, I. B. H. Capacidade aeróbica, força e resistência musculares de idosas praticantes de ginástica. Estudos interdisciplinares sobre o envelhecimento, Porto Alegre, v.23, n.3, p. 145-157, 2018.

LÜDKE M, ANDRÉ MEDA. Pesquisa em educação: abordagens qualitativas. São Paulo: EPU; 1986.

MARMELEIRA, J. An examination of the mechanisms underlying the effects of physical activity on brain and cognition. European Review of Aging and Physical Activity, Wingate, v.10, n.2, p.83-94, 2013.

\section{MATOS, J. A. S. A escola e o percurso} educativo de pessoas com paralisia cerebral: estudo de caso. 2011. $108 \mathrm{f}$. Dissertação (Mestrado em Educação) Faculdade de Educação, Universidade Federal da Bahia, Salvador, 2011.

PRANDINA, M. Z.; SANTOS, M. L. A educação física escolar e as principais dificuldades apontadas por professores da área. Horizontes - Revista de Educação, Dourados, v.4, n.8, julho a dezembro 2016.

RIMMER JH, RILEY B, WANG E, RAUWORTH A, JURKOWSKI J.

Physical activity participation among persons with disabilities: barriers and facilitators. American Journal of Preventive Medicine; 26(5):419-25, 2004.

ROSENBAUM, P. et al. A report: the definition and classification of cerebral palsy April 2006. Developmental
Medicine and Child Neurology, v. 109, p.8-14, 2007.

SEBASTIÃO, L. L.; FREIRE, E. S. A utilização de recursos materiais alternativos nas aulas de educação física: um estudo de caso. Revista Pensar a Prática, Goiânia, v.12, n.3, 2009.

YIN, R. K. Estudo de caso: planejamento e métodos. 4. Ed. Porto Alegre: Bookman, 2010.

YOSHIDA, D. et al. The relationship between physical fitness and ambulatory activity in very elderly women with normal functioning and functional limitations. Journal of Physiological Anthropology, London, v. 29, n. 6, p. 211-218, 2010.

ZUCHETTO, A. T. CASTRO R.L.V.G As contribuições das atividades físicas para a qualidade de vida dos deficientes físicos. Revista Kinesis, Santa Maria, v.26:52166, 2002. 